\title{
EVALUATION OF ORAL MUCOSITIS IN ORAL CANCER PATIENTS UNDERGOING RADIOTHERAPY
}

\author{
Barsha Bajracharya ${ }^{1}$, Subrata Bhattacharyya ${ }^{2}$, Pratibha Poudel ${ }^{3}$ \\ ${ }^{1}$ Department of Dentistry, Nepalese Army Institute of Health Sciences, Kathmandu, Nepal. \\ ${ }^{2}$ Department of Oral Pathology, Kantipur Dental College, Kathmandu, Nepal. \\ ${ }^{3}$ Department of Oral Pathology, Kathmandu University School of Medical Sciences, Dhulikhel, Nepal. \\ *Correspondence to: Dr. Barsha Bajracharya, Department of Oral Pathology, Nepalese Army Institute of Health Sciences, Kathmandu, Nepal. \\ Email: dr.barsha.bajracharya@gmail.com
}

\begin{abstract}
Introduction: The present study was conducted to evaluate oral mucositis in oral cancer patients receiving head and neck radiotherapy. Methods: Sixty oral cancer patients who had received at least $\mathbf{4 0}$ grays of radiation were included in the study. Mucositis was scored by oroscopy using WHO scale. Grades of mucositis were then compared with total dose of radiation received by the patients. Results: The cases were receiving the mean cumulative dose of standard radiation therapy of 2Gy per fraction, 5 fractions per week. All the patients developed oral mucositis. The majority had grade I mucositis, followed by grade III, II and IV. The grade of mucositis was directly proportional to the dose of radiation exposure. Conclusion: Oral mucositis occurs among all the patients undergoing head and neck radiotherapy and grade of mucositis is proportional to the dose of radiation exposure.
\end{abstract}

Key words: Oral cancer, Oral mucositis, Radiotherapy

\section{INTRODUCTION}

Oral mucositis (OM) is one of the major toxicities of ionizing radiation. About $80 \%$ of patients undergoing head and neck radiotherapy suffer from OM. ${ }^{1}$ They manifest as erythema or ulcerations (Figure 1). Erythematous mucositis appears 7 to 10 days after initiation of high-dose cancer therapy. Severity of mucositis increases with increase in dose of radiation. Mucositis is self-limited when uncomplicated by infection and heals within 2 to 4 weeks after cessation of radiotherapy. ${ }^{2}$ The standardized grading of mucositis severity with can be done with instruments such as the World Health Organization (WHO) criteria (Table 1). ${ }^{3}$ The objective of the current study was to evaluate the severity of mucositis is oral cancer patients receiving head and neck radiotherapy.

\section{METHODS}

This study was carried out in Bhaktapur Cancer Hospital, Bhaktapur Nepal from 30/08/2015 to
$11 / 12 / 2015$. Sixty oral cancer patients undergoing standard radiation therapy (2 Gy per fraction delivered five times per week) who had received at least 40 Gy radiation (at least 4 weeks duration) were selected.

Patient's data was collected regarding age, sex, primary tumor location, stage of disease and whether the patient was also receiving chemotherapy. Information was collected regarding the total radiation dose received by patient. Oral examination was done and mucositis grading was done according to WHO criteria (Table1). The findings were tabulated and SPSS version 23 was used for statistical analysis. $P$ value $<0.05$ was considered as statistically significant. WHO grading of mucositis was then compared with radiation dose.

\section{RESULTS}

Mucositis is a frequent complication during head and neck radiotherapy. In our study, all the cases 
undergoing head and neck radiotherapy had mucositis. The mean age of the cases was 57 years and more than two third $(73 \%)$ of them were men. The most common primary tumor location was tongue. The majority of cases were in TNM stage II and III. Cases were receiving the mean cumulative dose of standard radiation therapy of 2 Gy per fraction, 5 fractions per week. All the cases were receiving concomitant chemotherapy.

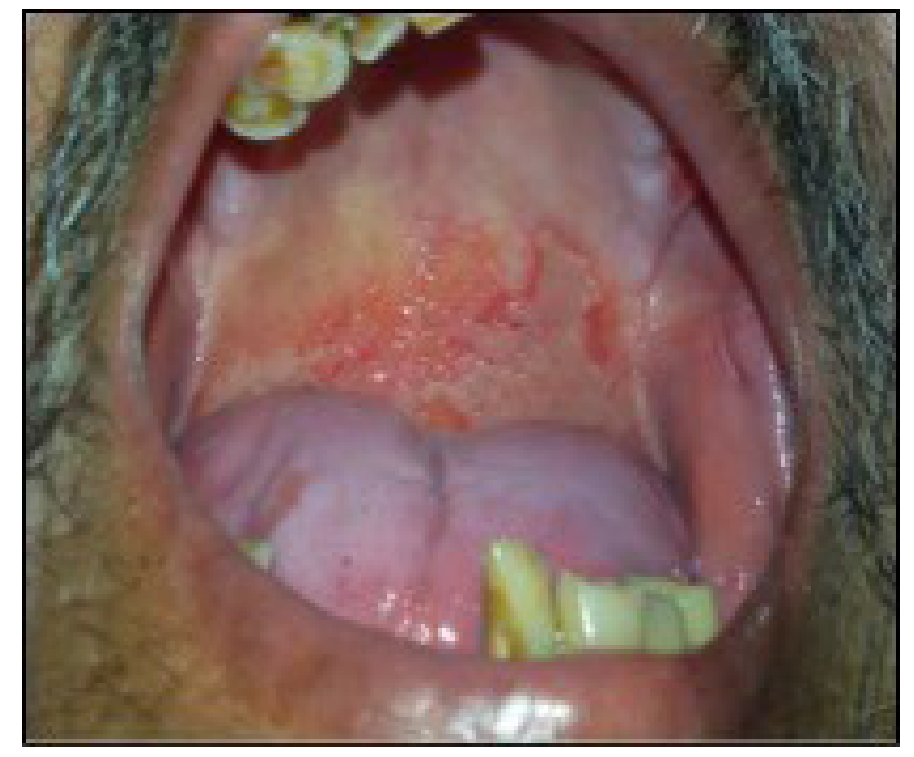

Fig 1: Grade 3 Oral Mucositis

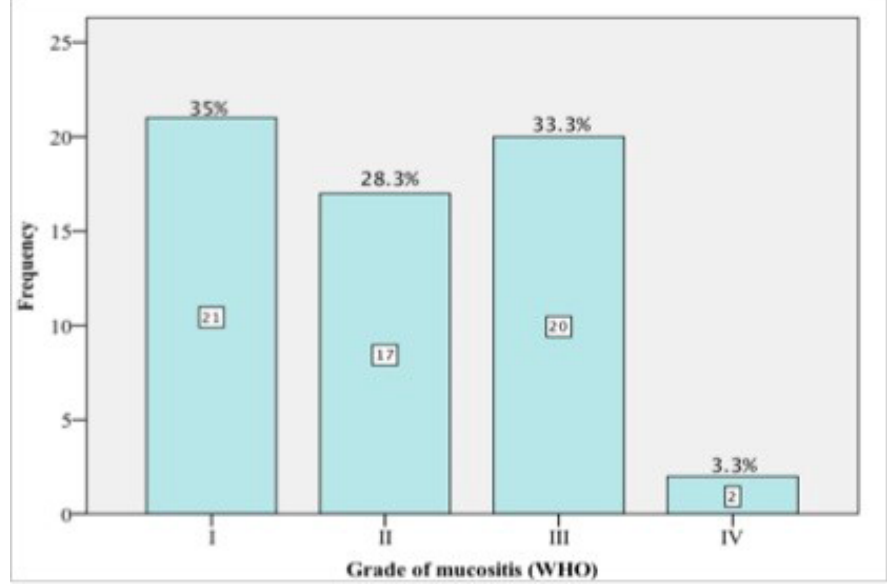

Fig 2: Prevalence of different grades of mucositis among cases $(n=60)$

The study showed that the majority of cancer patients had grade I (35.0\%) and Grade III (33.3\%) mucositis. $28 \%$ had grade II and 3.3\% had grade IV mucositis (Figure 2). Comparison between the different grades of mucositis and radiation dose (table 2) was made by One Way Analysis of Variance (ANOVA) test with Benferroni post hoc comparisons which showed that grades of mucositis was higher in patients with higher mean radiation dose, which reached statistical significance $p<0.05$. When we compared Grade I with other grades, the mean difference increased from Grade II to Grade IV with statistically significant results $(p<0.001)$. This highlights that mean dose of radiation exposure is directly proportional to grade of mucositis among patients undergoing head and neck radiotherapy. Similar were the results when Grade II was compared with Grade III and IV. However, though the patients experiencing grade IV mucositis had higher mean dose compared to Grade III, it did not reach statistical significance. $(p<0.167)$

Table 1. WHO criteria for grading of oral mucositis ${ }^{3}$

\begin{tabular}{|l|l|}
\hline Oral mucositis grades & Criteria \\
\hline Grade 1 & Soreness, erythema \\
\hline Grade 2 & Erythema, ulcers, can eat solid \\
\hline Grade 3 & Confluent ulcers, requires liquid diet only \\
\hline Grade 4 & Oral alimentation not possible, hemorrhage \\
\hline
\end{tabular}


Table 2: Comparison of mean values of radiation dose on the basis of WHO grading of mucositis among the cases.

\begin{tabular}{|c|c|c|c|c|c|}
\hline \multirow{2}{*}{$\begin{array}{c}\text { GROUP } \\
(\text { MEAN } \pm \text { SD })\end{array}$} & \multirow{2}{*}{$\begin{array}{c}\text { COMPARISON } \\
\text { GROUP } \\
(\text { MEAN } \pm \text { SD) } \\
\end{array}$} & \multirow{2}{*}{$\begin{array}{l}\text { MEAN DIFFER- } \\
\text { ENCE }\end{array}$} & \multicolumn{2}{|c|}{ 95\% CI OF MEAN DIFFERENCE } & \multirow[b]{2}{*}{ P VALUE } \\
\hline & & & LOWER & UPPER & \\
\hline \multirow{3}{*}{$\begin{array}{c}\text { GRADE I } \\
(46.00 \pm 2.60)\end{array}$} & $\begin{array}{c}\text { GRADE II } \\
(51.29 \pm 5.61)\end{array}$ & -5.294 & -8.43 & -2.16 & $0.001 *$ \\
\hline & $\begin{array}{c}\text { GRADE III } \\
(63.80 \pm 5.76)\end{array}$ & -17.80 & -20.80 & -14.80 & $<0.001^{*}$ \\
\hline & $\begin{array}{c}\text { GRADE IV } \\
(69.0 \pm 4.24)\end{array}$ & -23.00 & -30.11 & -15.89 & $<0.001^{*}$ \\
\hline \multirow{2}{*}{$\begin{array}{c}\text { GRADE II } \\
(51.29 \pm 5.61)\end{array}$} & $\begin{array}{c}\text { GRADE III } \\
(63.80 \pm 5.76)\end{array}$ & -12.50 & -15.68 & -9.34 & $<0.001 *$ \\
\hline & $\begin{array}{c}\text { GRADE IV } \\
(69.0 \pm 4.24)\end{array}$ & -17.70 & -24.89 & -10.52 & $<0.001 *$ \\
\hline $\begin{array}{c}\text { GRADE III } \\
(\mathbf{6 3 . 8 0} \pm \mathbf{5 . 7 6})\end{array}$ & $\begin{array}{c}\text { GRADE IV } \\
(69.0 \pm 4.24)\end{array}$ & -5.20 & -12.33 & 1.93 & 0.149 \\
\hline
\end{tabular}

*statistically significant.

\section{DISCUSSION:}

Oral mucositis was first termed as a side effect of radiotherapy in cancer patients in 1980.1 As tumor tissue and normal tissue response differently to radiation, fractionated radiation is used in head and neck cancer radiotherapy. Normal tissues are capable of repairing sub-lethal DNA damage, especially in the low dose range. Hence, 2 Gy fraction of radiation magnifies the differences in responses between tumor and normal tissues. The radiation dose depends on type of malignancy, location and whether or not radiotherapy will be used solely or in combination with other modalities. Recommended curative dose for head and neck carcinoma is between 50 Gy to $70 \mathrm{~Gy}$, given over a period of five to seven week, once a day, five days a week, 2 Gy per fraction. ${ }^{4}$

Oral mucositis is a multifactorial reactive inflammatory process. ${ }^{5}$ Radiation induces mitotic death of basal keratinocytes, leading to a gradual linear decrease in the number of epithelial cells. As the radiotherapy is continued, a steady state between death and regeneration of mucosal cells could occur. When the regeneration of cells fail to keep up with the rate of cell death, denudation of the mucosa occurs. ${ }^{6}$ It is postulated that mucositis evolve in five steps: initiation of primary damage, primary damage response, signal amplification, ulceration and healing. ${ }^{7}$ Hyperfractionated regimens and the use of conditioning and concomitant chemotherapy in particular increase the risk, severity, and duration of mucosal injury. ${ }^{8}$

Risk factors for oral mucositis are concomitant chemotherapy, bad oral hygiene, age, advanced disease and tumor stage, preexisting dental disease, use of tobacco and alcohol, changes in salivary flow and low leukocyte count. Elting et al. (2008) studied mucositis in patients who had received cumulative dose of at least $40 \mathrm{~Gy}$ of radiation therapy and concluded that all of the cases had mucositis, which was similar to our study. They also reported the risk of oral mucositis as $99 \%$. According to their study, use of chemotherapy doesn't significantly increase the risk of severe mucositis. ${ }^{9}$ Similarly, studies conducted by Epstein et al. (2000) ${ }^{10}$ and Herrstedt et al. $(2000)^{11}$ reported mucositis in $94 \%$ and $90 \%$ the cases undergoing head and neck radiotherapy respectively.

Studies have shown that OM may lead to interruption of treatment, placement of feeding tubes and hospitalization. The main preventive measure for 
$\mathrm{OM}$ is maintaining good oral care. Management of $\mathrm{OM}$ includes symptoms reduction and prevention of complications, including nutritional support, pain control, prophylaxis and treatment of secondary infections. $^{12}$

\section{CONCLUSION}

Patients of oral cancer receiving cumulative radiation doses of $40 \mathrm{~Gy}$ are likely to develop some degree of oral mucositis. Also, severity of oral mucositis depends on the dose of radiotherapy received by the patients.

\section{ACKNOWLEDGEMENT}

We are thankful to Bhaktapur Cancer Hospital for allowing us to carry out this study. We would also like to acknowledge all the faculties and staffs of Department of Oral Pathology of Kantipur Dental College.

\section{REFERENCES}

1. Maria OM, Eliopoulos N, Muanza T. RadiationInduced Oral Mucositis. Front Oncol. 2017;7:123.

2. Werbrouck J, De Ruyck K, Duprez F, Veldeman L, Claes K, Van Eijkeren M, et al. Acute normal tissue reactions in head-and-neck cancer patients treated with IMRT: influence of dose and association with genetic polymorphisms in DNA DSB repair genes. Int J Radiat Oncol Biol Phys. 2009;73(4):1187-95.

3. Naidu MUR, Ramana GV, Rani PU, Mohan lyyapu K, Suman A, Roy P. Chemotherapy-Induced and/ or Radiation Therapy-Induced Oral MucositisComplicating the Treatment of Cancer. Neoplasia. 2004;6(5):423-31.

4. Vissink A, Jansma J, Burlage FR, Coppes RP, Surgery $M$, Biology SC. Oral sequelae of head and neck radiotherapy. Crit Rev Oral Biol Med. 2003;14(3):199-212.
5. Belazi M, Velegraki A, Andreadis D, Hini S, Arsenis G. Oral Candida isolates in patients undergoing radiotherapy for head and neck cancer: prevalence, azole susceptibility profiles and response to antifungal. Oral Microbiol Immunol. 2004;19(6):347-51.

6. Sciubba JJ, Goldenberg D. Oral complications of radiotherapy. Lancet Oncol. 2006;7:175-83.

7. Kumar PSS, Balan A, Sankar A, Bose T. Radiation induced oral mucositis. Indian J Palliat Care. 2009;15(2):95-102.

8. Awwad HK, Lotayef $M$, Shouman $T$, Begg AC, Wilson G, Bentzen SM, et al. Accelerated hyperfractionation (AHF) compared to conventional fractionation (CF) in the postoperative radiotherapy of locally advanced head and neck cancer: influence of proliferation. Br J Cancer. 2002;86(4):517-23.

9. Elting LS, Keefe DM, Sonis ST, Garden AS, Barasch A, Tishler RB, et al. Patient-reported Measurements of Oral Mucositis in Head and Neck Cancer Patients Treated With Radiotherapy With or Without Chemotherapy and Impact on Quality of Life. Am Cancer Soc. 2008;2704-13.

10. Epstein JB, Gorsky M, Guglietta A, Le N, Sonis ST. The correlation between epidermal growth factor levels in saliva and the severity of oral mucositis during oropharyngeal radiation therapy. Cancer. 2000;89(11):2258-65.

11. Herrstedt J. Prevention and management of mucositis in patients with cancer: A review article. Int J Antimicrob Agents 16. 2000;16:1613.

12. Vera-Llonch M, Oster G, Hagiwara M, Sonis S. Oral mucositis in patients undergoing radiation treatment for head and neck carcinoma. Cancer. 2006;106(2):329-6. 